\title{
Artes de ensinar, ofício de viver: das narrativas (auto)biográficas a uma história pública dos professores
}

Arts of Teaching, Craft for Life: From (Auto)Biographical Narratives to a Public History of Teachers

Everardo Paiva Andrade *, Juniele Rabêlo de Almeida $* *, 2$ Mariana Mizael Pinheiro da Silva ${ }^{* * *, 3}$

\section{Resumo}

$\mathrm{O}$ artigo aborda a interface entre trajetórias docentes e história pública, a partir de reflexões que apontam os professores como sujeitos dos seus saberes e práticas, bem como produtores de sua própria história. Busca o cruzamento das trajetórias de vida e das inventividades docentes ao reconhecer a potência das narrativas (auto)biográficas para significação compartilhada, no espaço público, das artes de ensinar. Procura experimentar possibilidades teórico-metodológicas, por meio da construção e da consolidação do acervo Trajetórias Docentes - composto por entrevistas públicas e memoriais de professores em variados contextos de formação. Trata ainda de interpretações acerca dos diferentes modos de olhar as práticas docentes, a partir do sentido

\begin{abstract}
This article deals with the interface between the trajectories of teachers and public history through reflections which show teachers as subjects of their own knowledge and practices, as well as producers of their own history. It seeks an intersection between life histories and teacher inventiveness by recognizing the potential of (auto)biographical narratives for shared meaning in the public space of the arts of teaching. Also aimed at is experimentation with theoretical and methodological possibilities through the construction and consolidation of the collection Teacher Trajectories - composed of public interviews and the memoires of teachers in various contexts of education. Finally, interpretations of the different modes of teaching practices are looked at, based on the
\end{abstract}

\footnotetext{
* Universidade Federal Fluminense (UFF), Programa de Pós-Graduação da Faculdade de Educação e do ProfHistória. Niterói, RJ, Brasil. everardo_andrade@uol.com.br

** Universidade Federal Fluminense (UFF), Programa de Pós-Graduação em História, Niterói, RJ, Brasil. junielerabelo@gmail.com

*** Rede Municipal de Ensino de Saquarema e de Rio Bonito, professora de Geografia, Saquarema, RJ, Brasil.mari.mizael@hotmail.com
} 
catalisador da aprendizagem narrativa, para construção de uma história pública dos professores.

Palavras-chave: trajetórias de vida; inventividades docentes; autobiografia; aprendizagem narrativa; história pública. catalyzing meaning of narrative learning, for the construction of a public history of teachers.

Keywords: life trajectories; teachers' inventiveness; autobiography; narrative learning; public History.

Nesta vida morrer não é difícil

Difícil é a vida e seu ofício

(V. Maiakóvski)

O presente texto pretende refletir sobre os professores como sujeitos dos seus próprios saberes e práticas - lugar social para a análise das suas trajetórias de vida e das inventividades docentes. Busca ainda experimentar possibilidades teórico-metodológicas para análise dos diferentes modos de olhar o professor e sua prática. $\mathrm{O}$ objetivo final do artigo consiste em construir referências para a consolidação do acervo Trajetórias Docentes, ${ }^{4}$ por meio das discussões sobre aprendizagem narrativa ${ }^{5}$ história pública. ${ }^{6}$

Ainda em 1987, o pesquisador norte-americano Lee S. Shulman afirmava:

Uma das frustrações do ensino como ocupação e como profissão é sua grande amnésia individual e coletiva, a constância com que as melhores criações dos professores são perdidas para seus pares, tanto contemporâneos como futuros. Diferentemente de campos como a arquitetura (que preserva suas criações em plantas e edifícios), o direito (que constrói uma literatura de casos, de opiniões e interpretações), a medicina (com seus registros e estudos de casos) e mesmo diferentemente do xadrez, do bridge ou do balé (com suas tradições de preservar jogos memoráveis, coreografias e performances mediante formas inventivas de anotação e registro), o ensino é conduzido sem uma audiência dos pares. O ensino é desprovido de uma história da prática. (Shulman, 1987, tradução nossa)

A importante reflexão de Shulman (1987) prenunciava o esforço de pesquisadores para compreender o que é a docência, com base não em prescrições externas, mas nos conhecimentos, isto é, no que pensam e fazem os próprios professores de ofício, sobretudo a partir do que ele próprio nomeia casos de perícia. Nesse contexto de pesquisa, Shulman irá cunhar o conceito de racionalização pedagógica (uma operação que envolve seis passos consecutivos e 
articulados: compreensão, transformação, instrução, avaliação, reflexão e nova compreensão).

Muita coisa aconteceu desde então na pesquisa sobre a formação e a profissão docente, sobretudo aquela que focaliza a prática ou os saberes práticos e experienciais mobilizados pelos professores na arte de ensinar. Nesse mesmo sentido, Clermont Gauthier (Gauthier et al., 2006) e colaboradores desenvolveram um amplo programa de pesquisas visando constituir uma teoria da Pedagogia assentada na observação direta dos professores em seus espaços de trabalho, visando um repertório de conhecimentos do ensino, publicamente validado pelos critérios da pesquisa científica. Já Maurice Tardif (2002), procurando responder a uma pergunta - afinal, o que sabem os professores que os torna sujeitos profissionais particulares no âmbito das sociedades modernas? -, acaba por estabelecer uma problemática dos saberes docentes, com ênfase na objetivação parcial de seus saberes experienciais, como condição básica para um novo profissionalismo. Ainda, nesse mesmo contexto, as pesquisas sobre ciclos de vida de professores, de Michael Huberman (1992), e as histórias de vida e carreira dos professores empreendidas pelo historiador inglês Ivor F. Goodson (1992) fornecem uma chave para a compreensão das práticas pedagógicas de uma perspectiva que compreende o currículo como prescrição, mas também como prática. Por fim, vale mencionar ainda as biografias educativas, que aparecem em trabalhos como os de Pierre Dominicé, Gaston Pineau e António Nóvoa (1992).

De diferentes maneiras, todos esses trabalhos ecoaram no Brasil, nas décadas seguintes, nas pesquisas de Ana Maria Monteiro (2007), perguntando como os professores de história mobilizam os saberes para ensinar o que ensinam, ou de Selva Guimarães Fonseca (1997), investigando o desenvolvimento pessoal e profissional de professores de história na perspectiva da história oral de vida. Com distanciamento, talvez seja possível observar que tenha faltado à reflexão de Shulman uma pergunta crucial sobre como a prática funciona, como observar o efêmero e o ordinário para compreender a oralidade e a operatividade que alicerçam uma cultura ordinária comum, nos termos do trabalho que Michel de Certeau (Certeau, 1998; Certeau; Giard; Mayol, 2013) e seus colaboradores desenvolveram em paralelo para compreender as artes cotidianas do fazer. Uma pesquisa que se mostrará fértil no estudo das redes de relações sutis que constituem a memória de uma profissão, capaz de revelar 
o professor como presença, corpo em movimento e voz sonora, de uma perspectiva tríplice, como corporalidade, vocalidade e também performance (Zumthor, 2014).

\section{Praticantes ordinários das Artes de Ensinar: QUANDO O PERIFÉRICO É VISTO COMO INVENTIVO}

Dentre uma multiplicidade de perspectivas que cercam a problemática anunciada, esta seção do artigo toma como fio orientador uma abordagem que almeja partir dos professores, no intuito de ressoar vozes escolares que anunciam o enfrentamento de uma realidade educacional silenciadora, branqueada e sexista. Nesse sentido, a inquietação que move as análises, e que segue dando sentido ao aprofundamento do entendimento das artes de ensinar, fundamenta-se no reconhecimento da autoria docente. Ao invés de uma prescrição do que os professores devem fazer e/ou devem aprender, torna-se indispensável compreender o que já sabem e fazem. Diante disso, é de se inquietar com o discurso das ausências que paira sobre a escola, embora as contribuições do campo da chamada Epistemologia da Prática no Brasil já tenham quase 30 anos - apesar de as pesquisas serem consideradas recentes.

Parte-se, portanto, da percepção de que os professores estão situados em um contexto de desconfiança, em relação tanto às suas práticas quanto aos seus saberes. Em caráter amplo, a ideia de sujeitos periféricos pode abarcar aqueles que se situam às margens das relações de poder na sociedade, particularmente na interface com questões relativas à Educação, podendo representar diferentes atores sociais. Ao posicionarmos os professores como sujeitos periféricos, no entanto, entendemos serem elucidativas as considerações trazidas por Selles e Andrade (2016) acerca da autonomia docente para, desse modo, reposicioná-los em um lugar social mais fértil para a análise das suas inventividades. Assim, tendo como sentido de autonomia o trânsito entre o desejável e o possível, Selles e Andrade (2016, p. 49) consideram "autonomia como o resultado de um jogo jogado, envolvendo regulação, resistência e modulação. Dizendo de outro modo, longe de constituir uma essência idealizada ou perdida, a autonomia surge como relação, com importantes implicações identitárias".

Em uma compreensão relacional de autonomia docente - o que chamam de "jogo jogado" -, os autores argumentam em torno de um espaço de 
fronteiras em que estão imbricadas formas de controle e de criação, interpretadas a partir dos conceitos de estratégias e táticas, de Michel de Certeau. Não há, portanto, uma autonomia, mas autonomias possíveis dentro do "jogo pedagógico" que disputam o saber e o fazer docente, em uma interpretação que não a reduz à regulação ou à soberania. Assumindo essa proposta de sentido para a autonomia docente como distante de ser facilmente apreendida teórica e concretamente, a ideia central que delineia essa compreensão é a de que "diferentes estratégias buscam regular o trabalho docente, e que, no âmbito de suas práticas, os professores implementam táticas que modulam tais projetos de regulação" (Selles; Andrade, 2016, p. 39).

A periferização do trabalho docente, nesse sentido, é lida na dimensão da subalternização, por meio da regulação pelas políticas públicas, em especial pelas políticas curriculares. A regulação do trabalho docente recoloca em cena, mais uma vez, a perspectiva dos professores enquanto aplicadores de políticas e de conhecimentos externos preestabelecidos, como têm delineado as políticas públicas atuais. Redimensiona-se, aqui, para a ideia do professor enquanto um sujeito produtor de políticas públicas - a partir da sua trajetória e inventividades docentes expressas em narrativas (auto)biográficas, ultrapassando, assim, o lugar à margem das tomadas de decisão em relação ao núcleo da sua profissionalidade, afinal, tais políticas educacionais verticalizadas tornam os docentes possíveis sujeitos subalternizados. Esse alerta trazido por Selles e Andrade (2016), todavia, se apresenta ampliado em outras esferas que compõem o que os autores chamam de estratégias de regulação, as quais seriam:

(i) o Estado, a burocracia estatal e as políticas públicas educacionais; (ii) o mercado, a lógica mercantil e privatista em educação e a indústria cultural, especialmente o setor de produção didático-pedagógica; (iii) a pesquisa acadêmica compreendida em uma perspectiva prescritiva, que toma a educação, a escola e a profissão docente não pelo que efetivamente são, mas pelo que lhes falta ou pelo que deveriam ser; (iv) o movimento social dos professores e as iniciativas de organização e de mobilização sindical, numa perspectiva ético-profissional; (v) o currículo e a própria estrutura disciplinar do trabalho docente, envolvendo demandas internas de gestão e externas, do âmbito do que tem sido chamado de noosfera. (Selles; Andrade, 2016, p. 44-45) 
Diferentemente do foco dos autores a propósito das políticas públicas educacionais, no entanto, o ponto de partida deste texto consiste em atentar para a regulação presente no terceiro tópico indicado, que diz respeito às pesquisas acadêmicas prescritivas que, por vezes, tornam os professores sujeitos periféricos do seu próprio saber e fazer. Os investigadores e a pesquisa educacional, como citado por Selles e Andrade (2016) a partir de António Nóvoa, podem se conformar enquanto parte desse discurso que se coloca como regulador. O que se pauta é que a desconsideração da cultura docente pode afirmar um discurso que é desqualificador, por meio do qual os professores tornam-se objetos, simples replicadores. Essa denúncia acerca da colonização acadêmica sobre a escola, então, torna importante que as pesquisas contribuam para um processo permanente de solidariedade com a perspectiva política e epistemológica de "culturas docentes valorizadas e fortalecidas", como salientam Selles e Andrade. Seguindo essa agenda posta pelos autores em relação à construção de modos de entendimento da docência que não sejam imposições ou modelos, consideramos que a autonomia docente é potencializada quando os professores são compreendidos como praticantes ordinários das artes de ensinar.

A posição de ordinário, segundo a perspectiva trazida por Certeau, é o que nos possibilita realçar a dimensão inventiva da autonomia. Essa outra extremidade, da qual eles falam, leva em conta os sujeitos e as mediações construídas nesse lugar do encontro entre professores e estudantes, que os reporta às histórias de vida, aos laços profissionais locais e aos pactos com a gestão escolar. As referências táticas, por conseguinte, nos aproximam do cotidiano e das práticas comuns, que são o lugar do ordinário. Apesar de o comum ser alvo da admiração, a opção por entender os professores como praticantes ordinários não os retira do campo profissional que ocupam, ao contrário, afirma a profissão docente. Ocupar o lugar de ordinário é chamar atenção, a partir de outra lógica, para o que já é hipoteticamente conhecido. Hipoteticamente no sentido de que, por vezes, se expressa em uma "multidão sem rosto", genericamente, algo que só se compreende em profundidade por meio de uma ciência prática do singular (Certeau; Giard; Mayol, 2013).

O discurso social e acadêmico de desprestígio da profissão docente está fundamentado, por esse ângulo, no não reconhecimento das minúcias dos mecanismos que a constituem. Na contramão da desprofissionalização que, como aponta Nóvoa (2017), se evidencia entre outras maneiras, pelos baixos 
salários, condições precárias nas escolas, lógicas de burocratização e controle, e visão técnica e prática do trabalho, está a proposta de apreensão do processo profissional artesanal e astucioso que caracteriza a docência. Postas essas questões, acreditamos ser imprescindíveis alguns cuidados analíticos para que o entendimento das artes de ensinar, ao qual se propõe este texto, não se configure em regulação. Desse modo, seguimos com encaminhamentos teórico-metodológicos que compreendemos ser pertinentes para o desenvolvimento dessa investigação - sobre as possibilidades férteis que se apresentam para nos aproximarmos da "cultura docente em ação" (Tardif), inscritas no diálogo entre professores e estudantes.

\section{COMO INTERPRETAR AS PRÁtiCAS ORDINÁRIAS DAS INVENTIVIDADES DOCENTES?}

Como posso dialogar, se alieno a ignorância, isto é, se a vejo sempre no outro, nunca em mim? Como posso dialogar, se me admito como um homem diferente, virtuoso por herança, diante dos outros, meros "isto", em quem não reconheço outros eu? (Freire, 1987, p. 46)

Sempre bom lembrar que não se deve tomar os outros por idiotas. (Giard apud Certeau, 1998, p. 19)

Essas advertências - que refletem preocupações, vigilâncias e, sobretudo, a confiança no Outro, que têm sua origem na intenção de fazer provocações que preservem em si finalidades diferentes -, trazem indicações sobre o método de pesquisa que são essenciais. Uma questão fundamental está em tomar como pressuposto o ultimato de que o anseio pela apreensão das inventividades não pode ser alcançado quando a pesquisa é um fazer arrogante, ou o outro é visto como "idiota". Diante disso, a busca pela construção de modos de entendimento da docência sugere, para essa compreensão, dois movimentos teórico-metodológicos necessários: por um lado, aquele que parte da desconstrução analítica que pressupõe um distanciamento entre o professor e ele mesmo, isto como fundamento para as escolhas subjetivas da sua identidade docente; por outro, a fabricação de lentes sensíveis para a compreensão dos arranjos singulares dos contextos escolares, e do professor como praticante ordinário. 
2.1 Das trajetórias de vida às cartografias das práticas: narrativas (auto) biográficas

Com a intenção de investigar as trajetórias docentes, nos posicionamos diante das possibilidades de ler os cotidianos escolares que resguardam uma estreita relação entre vida e profissão. Essa é uma questão para a investigação, na medida em que compreendemos que há que se usar lentes que permitam a explicitação desse emaranhado entre profissão e sujeito, entre a vida no sentido lato e a vida profissional. Posto que o trabalho de memória circunscreve-se entre as histórias de vida e as inventividades docentes, a (auto)biografia parece ser uma abordagem coerente com a perspectiva de análise que se pretende desenvolver, uma vez que

permite que seja concedida uma atenção muito particular e um grande respeito pelos processos das pessoas que se formam: nisso reside uma das suas principais qualidades, que o distinguem, aliás, da maior parte das outras metodologias de investigação em Ciências Sociais. Respeitando a natureza processual da formação, o método biográfico constitui uma abordagem que possibilita ir mais longe na investigação e na compreensão dos processos de formação e dos subprocessos que o compõem. (Nóvoa; Finger, 2014, p. 21)

Ferrarotti, nesse mesmo livro organizado por Nóvoa e Finger (2014), em texto redigido em 1979, constrói uma reflexão que tem como cerne as questões epistemológicas acerca do método (auto)biográfico, com a intenção de apontar algumas das suas especificidades no campo das ciências sociais (Ferrarotti, 2014). O autor faz um percurso em que delineia as causas que culminaram no crescimento do interesse pelo uso sociológico da biografia, que chamou de razões de um revival. A ideia de retomada se coloca na medida em que essa perspectiva metodológica data de fins do século XIX, já como alternativa à sociologia positivista, sendo sistematizada pela Escola de Chicago nos anos 1920/1930. O revival se deu por duas questões principais. A primeira delas foi a necessidade de renovação da metodologia clássica das ciências sociais, embasada no axioma da objetividade. A outra seria a exigência de uma nova antropologia que avançasse em relação às insuficiências das investigações sociológicas para pensar os problemas do cotidiano por meio das explicações 
estruturais. $\mathrm{O}$ autor situa o retorno à biografia, assim, em função de uma crise do método.

Saindo das ciências sociais e indo para o campo da pesquisa em Educação, no Brasil, Passeggi e Souza (2017) contextualizam a inserção das narrativas orais e escritas como reflexo da crise dos grandes paradigmas do behaviorismo e do estruturalismo, nos anos 1980, abrindo horizontes para o "retorno do sujeito". Apontam para o processo de aproximação entre a narrativa da literatura e o campo científico. No entanto, dentro da diversidade de possibilidades narrativas, destacam que o recorte da pesquisa (auto)biográfica são as narrativas (auto)biográficas, isto é, "aquelas em que o narrador ou a narradora elabora a sua própria história e nela se projeta, ao mesmo tempo, como personagem e autor ou autora da reflexão conduzida" (Passeggi, 2016, p. 306). Dentro dessa compreensão, Passeggi e Souza (2017) apresentam quatro grandes orientações relacionadas às narrativas (auto)biográficas no Brasil: fenômeno antropológico; fonte e método de pesquisa qualitativa; dispositivo de pesquisa-formação; e como estudo da natureza e diversidade discursiva da biografização da vida.

No contexto desta pesquisa, pautamos nosso interesse nas narrativas como fonte e método para indagar o conhecimento das práticas dos professores e os sentidos dados a elas pelos próprios sujeitos (Passeggi, 2016). Alguns questionamentos nos acompanham: afinal, de que modo as inventividades pedagógicas se apresentam singularizadas nas histórias de vida dos professores? $\mathrm{O}$ método (auto)biográfico contribui para que se possa observar a construção das narrativas dos professores (praticantes ordinários) sobre si e sobre a docência, em um deslocamento que é particular e, também, coletivamente marcado pelas relações com os muitos "outros" que cruzam a vida e a profissão. Não se trata puramente de uma narrativa individual, e sim de parte de um contexto em que o sujeito se insere, marcado por seus entendimentos. Essa interpretação da pesquisa se alicerça, nesse sentido, em elementos subjetivos que envolvem os aspectos pessoais e os seus transbordamentos para os sentidos dados à profissão, em que se levam em consideração prismas que, em geral, são desinteressantes para a produção do conhecimento científico. Como sugerem Passeggi e Souza (2017), tomar o (auto)biográfico como objeto de estudo carrega em si uma dimensão de "ousadia", que se sustenta em três apostas epistemológicas de diferentes ordens. Nas palavras dos autores, eles assim distinguem: 
Recorremos ao termo aposta para sinalizar o engajamento, o desafio dessa aventura (auto)biográfica no mundo científico. Uma aposta de caráter epistemopolítico, que coloca no centro do processo a capacidade humana de reflexividade autobiográfica do sujeito, permitindo-lhe elaborar táticas de emancipação e empoderamento suficientemente boas para superar interpretações culturais excludentes, que o oprimem. Uma aposta pós-colonial que se opõe a uma visada elitista do conhecimento que desconhece essa capacidade de reflexividade humana e de interpretação do cidadão "comum" que sofre as pressões cotidianas que o destituem dos seus direitos e embotam sua consciência crítica. Finalmente, uma aposta pós-disciplinar, ancorada na liberdade de ir e vir em busca de instrumentos heurísticos onde eles se encontram, como sugere Ferrarotti [...] sem se acomodar aos quadros de uma visão disciplinar, ou inter, ou pluri- ou multi- ou transdisciplinar. (Passeggi; Souza, 2017, p. 10)

Sobre a aposta epistemopolítica, citando Boaventura de Sousa Santos e a sua compreensão de desperdício de experiências, os autores assinalam que um dos anseios do movimento (auto)biográfico é o de retornar ao sujeito empírico, com foco nas suas experiências. Por meio da perspectiva epistemopolítica de Pineau e Le Grand (2012), argumentam contra uma ciência positivista e colonizadora.

As narrativas propõem uma nova episteme, um novo tipo de conhecimento, que emerge não na busca de uma verdade, mas de uma reflexão sobre a experiência narrada, assegurando um novo posicionamento político em ciência, que implica princípios e métodos legitimadores da palavra do sujeito social, valorizadores de sua capacidade de reflexão, em todas as idades, independentemente do gênero, etnia, cor, profissão e posição social, entre outras opções. (Passegggi; Souza, 2017, p. 10)

Dessa mesma aposta de posicionamento político em ciência emerge a inquietação sobre as possibilidades de uma pesquisa (auto)biográfica para a produção de um conhecimento pautado em sujeitos de carne e osso. O método (auto)biográfico, desse modo, tem se mostrado como uma perspectiva útil à apreensão do potencial explicativo das trajetórias de vida acerca da profissão docente. 


\subsection{Cartografando as práticas docentes:}

\section{inspirações a partir de Michel de Certeau}

O que conduz os esforços do texto, neste momento, é a complexidade inerente ao entendimento das Artes de Ensinar enquanto práticas ordinárias. Ao nos guiarmos pelo pressuposto de que as práticas dos professores são do tipo tático (Certeau, 1998) - e, por isso, artes de ensinar -, considera-se que há uma provisoriedade intrínseca nessa concepção, permeada por um olhar específico para a leitura das criações curriculares. Em outras palavras, questiona-se: como interpretar, em profundidade, as minúcias que caracterizam os mecanismos efêmeros de criação das inventividades docentes? Antecipadamente, nos colocamos vigilantes em relação à afirmação feita por Certeau de que desconhecemos as operações que alicerçam as práticas ordinárias: "Conhecemos mal os tipos de operações em jogo nas práticas ordinárias, seus registros e suas combinações, porque nossos instrumentos de análise, de modelização, e de formalização foram construídos para outros objetos e com outros objetivos" (Certeau; Giard; Mayol, 2013, p. 341).

Distante da proposição de um modelo replicável de análise, temos pistas das formas de interpretação dos movimentos de repetição, característicos do cotidiano, em meio às complexidades aparentemente simples: “O essencial do trabalho de análise que deveria ser feito deverá inscrever-se na análise combinatória sutil, de tipos de operações e de registros, que coloca em cena e em ação um fazer com, aqui e agora, que é um ato singular ligado a uma situação, circunstâncias e atores particulares” (Certeau; Giard; Mayol, 2013, p. 341).

É possível analisar a cultura ordinária por meio dos seus usos, como ela é praticada - nos códigos particulares dos praticantes, ao invés da leitura homogeneizadora dos modelos analíticos largamente utilizados. Para Certeau (Certeau; Giard; Mayol, 2013), deve-se reconhecer como prioridade os alicerces que a sustentam e organizam: a oralidade, a operatividade e o ordinário. A trivialidade do cotidiano, no entanto, encobre o enredamento de saberes e práticas constituintes dos hábitos banais, que para a sua captura há que se voltar para aquilo que durante muito tempo para a ciência - e que ainda perdura - foi tido como ilegítimo e/ou negligenciável. Isto é, a cultura oral, os praticantes e a vida comum.

À vista disso, os escritos do autor são provocadores quando pensados a partir da escola, que é marcada, de algum modo, por esse tripé de elementos 
que compreendemos ser também férteis para a apreensão da cultura escolar. Essa cultura, portanto, para além da superficialidade da repetição e da análise simplificadora, em direção a uma leitura da sua produção de singularidades, vista a partir dos usos ordinários.

Desse modo, com a intenção de nos permitir "imaginar a incrível abundância inventiva das práticas cotidianas" (Certeau; Giard; Mayol, 2013, p. 342), argumentaremos em torno da oralidade e da operatividade como possíveis chaves analíticas para as práticas escolares ordinárias, buscando justificar sua utilização como parte da construção teórico-metodológica da pesquisa.

\section{NARRATIVAS SOBRE O COTIDIANO ESCOLAR:}

ORALIDADE, CORPO E PRODUÇÃO DE SENTIDO

Para Certeau (Certeau; Giard; Mayol, 2013), o reconhecimento da oralidade dentro da cultura é uma exigência, por ela ter papel fundante na relação com o outro, e como constituinte das configurações que se estabelecem no cotidiano. O que se coloca é: não há comunicação social sem a oralidade, ainda que a escrita tenha se tornado um veículo organizador do mundo. Ela é situada, assim, em duas dimensões que se enlaçam: a do aprender e a da comunidade. Destacar o papel da oralidade na circulação do saber na sociedade, seus rituais de mensagens entre sons, sentidos e corpos, impõe de imediato remeter-se ao professor e à escola. As trajetórias e inventividades docentes se expressam na oralidade, que é organizadora e reorganizadora desse lugar por meio das "músicas de sons e de sentidos, polifonias de locutores que se buscam, se ouvem, se interrompem, se entrecruzam e se respondem" (Certeau; Giard; Mayol, 2013, p.336), ainda que a escola represente um lócus de hipervalorização da escrita na construção oficial do conhecimento.

Porém, estando naturalizada a presença da oralidade em todos os espaços, "como creditar inteligência e complexidade requintada às astúcias de uma prática tão comum?” (Certeau; Giard; Mayol, 2013, p. 338). Essa reflexão de Certeau, se trazida para o universo da sala de aula, nos faz perguntar: como creditar inteligência e complexidade requintada às artes de dizer que são, por vezes, tratadas enquanto apenas "cuspe e giz"? O que nos movimenta, nesse sentido, são as possibilidades de reinterpretar o "cuspe e giz" por outro viés, que não o da repetição e da monotonia. O que nos inquieta é o que não se sabe 
sobre o "cuspe e giz", ou, ainda, o questionamento: qual é a "poética escondida" nessa prática tão comum? De outra natureza, pensando nas artes de ensinar, o saber docente não se materializa na escrita, mas na aula falada, nas explicações e gestos e, portanto, na oralidade. Desse modo, compreendemos que por meio da produção de presença (Gumbrecht, 2010) seja possível apreender parte desses códigos presentes na relação ensino-aprendizagem. Sem, contudo, como aponta Certeau (Certeau; Giard; Mayol, 2013), deixar de atentar para as informações complementares que as cercam, ou seja, além do dito e do enunciado, também os gestos, as pausas, os tons e os silêncios.

Certeau destaca que a produção do conhecimento presente na oralidade é um jogo complexo em que se faz necessário compreender as situações de interlocução para ir além na interpretação que se dá de forma pura e simples por meio dos significantes presentes nos enunciados. $\mathrm{O}$ autor destaca o ilocutório.

Prioridade do ilocutório, àquilo que não diz respeito à palavra nem à frase, mas à identidade dos locutores, à circunstância, ao contexto, à "materialidade sonora" das palavras trocadas. Aqui se insinua toda a inventividade dos "jogos de linguagem”, através de uma encenação de conflitos e de interesses assinalados a meia-palavra: artimanhas, desvios semânticos, quiproquós, efeitos sonoros, palavras inventadas, palavras deformadas, à maneira do Saperleau de Gildas Bourdet, diálogos que proliferam e viajam ao longe, com aquela distanciação e aquela indexação cheias de humor que as pessoas simples usam para arranjar-se com o desconforto da vida e pôr a ridículo os slogans do dia. (Certeau; Giard; Mayol, 2013, p. 338)

Quando o sinal toca, marcando o final do encontro daquela turma com aquele professor, inevitavelmente perde-se o registro daquela inventividade minúscula, que só será medida e valorizada, ou não, nos termos da cultura escolar, por meio das atividades, testes e trabalhos que, em geral, apagam sua origem na oralidade. Esse cenário cotidiano de anônimos "jogos da linguagem”, constituído por meio de conflitos e interesses que ultrapassam as palavras, que se insinuam por meio da identidade dos interlocutores, das circunstâncias, dos contextos e da "materialidade dos sons", é o que almejamos alcançar para a captura das Artes de Ensinar. O que se pretende, desse modo, é perceber essa condição que é efêmera por si mesma, sendo um momento 
singular de interação, enquanto uma complexidade requintada que está próxima da invisibilidade ao fim de cada aula.

\section{O ENSINO COMO UMA OPERAÇÃO DE PRATICANTES}

A cultura, nas sociedades de consumo, não é vista por Certeau por meio da detenção de bens ou da capacidade de estes manipularem as pessoas comuns. O que o interessa são as inúmeras operações que se dão na atividade dos praticantes com esses produtos culturais, em função dos seus objetivos e relações sociais. A operatividade, desse modo, é a criatividade dos modos de uso das coisas na vida. Assim, em uma analogia entre cultura e arte:

A cultura se julga pelas operações e não pela possessão dos produtos. $\mathrm{Na}$ arte, entender um quadro é reconhecer os gestos que lhe deram origem, a 'pincelada', o 'pincel', a 'paleta' do pintor. A arte da cozinheira é totalmente produção, a partir de uma escolha limitada de ingredientes disponíveis, numa combinação de gestos, de proporções, de utensílios e de meios de transformação ou de cocção. (Certeau; Giard; Mayol, 2013, p. 339)

Os gestos e as escolhas que buscamos reconhecer são, justamente, as operações de sutileza, materiais didáticos e palavras que envolvem a criação como parte do corpo a corpo da ação docente. A criação, no entanto, não no sentido da inovação ou do espetáculo, mas dos processos inventivos de construção das aulas a partir dos objetivos traçados. Ao nos apropriarmos da analogia feita por Certeau (Certeau; Giard; Mayol, 2013), percebemos ser interessante ter os sentidos voltados para o reconhecimento da "pincelada", do "pincel" e da "paleta" do professor para compreendermos as operações presentes no ensinar. Mas qual seria a "pincelada", o "pincel” e a "paleta" que estão na origem dessa operação específica? Das suposições admissíveis, imaginamos a pincelada como um estilo próprio. É possível que seja a pincelada que confira a autoria desta arte própria de ensinar. Seria, então, a identidade docente, submersa na relação entre vida e profissão já apontada, que possibilitará acessar indiretamente parte do saber que se expressará nas maneiras de ensinar. A pincelada, no entanto, está imediatamente relacionada aos usos dos pincéis. Talvez cuspe, 
giz, livro didático... Eles que produzirão efeitos específicos e múltiplos, caracterizando-a.

Por último, a paleta. Ela é um dos instrumentos mais importantes para o artista, onde ele dispõe e combina suas tintas. Na sala de aula, todavia, há uma especificidade: as cores têm vida própria e também pintam: os estudantes. $\mathrm{O}$ que faria o professor sem essa paleta colorida? As operações, assim, são compostas pela combinação de atores - alunos e professores - em uma situação singular: a aula. Ainda que sejam aproximações a serem exploradas no processo de pesquisar, que está intimamente relacionado à parte empírica da construção do trabalho, isto é, ao ver, ouvir e sentir, enfatiza-se que essas nuances devem envolver o tratamento das operações docentes que, segundo Certeau, possuem três aspectos: estético, polêmico e ético.

Um primeiro aspecto dessas operações é o estético: uma prática cotidiana que abre um espaço próprio numa ordem imposta, exatamente como faz o gesto poético que dobre ao seu desejo o uso da língua comum num reemprego transformante. Um segundo aspecto é polêmico: a prática cotidiana é relativa às relações de força que estruturam o campo social e o campo do saber. Apropriar-se das informações, colocá-las em série, montá-las de acordo com o gosto de cada um é apoderar-se de um saber e com isso mudar de direção a força de imposição do totalmente feito e totalmente organizado. É traçar o próprio caminho na resistência do sistema social com operações quase invisíveis e quase inomináveis. Um último aspecto, enfim, é ético: a prática cotidiana restaura com paciência e tenacidade um espaço de jogo, um intervalo de liberdade, uma resistência à imposição (de um modelo, de um sistema ou de uma ordem): poder fazer é tomar a própria distância, defender a autonomia de algo próprio. (Certeau; Giard; Mayol, 2013, p. 339-340)

Tanto nas artes de morar e cozinhar quanto nas artes de ensinar, há que se atentar para esses prismas na construção de uma compreensão do campo de ação da operatividade dos praticantes. Sob hábitos banais tem-se tentativas de transformação, relações de poder e de resistência que organizam e reorganizam as possibilidades de convívio entre professores e alunos, a partir dos interesses de docentes e discentes. Entender essas operações é um meio de apreender os processos cognitivos de aprendizado realizados à maneira da cultura escolar, embora possam se expressar de modo parcial e fragmentado 
e, possivelmente, não integralmente consciente, em um quebra-cabeças de comportamentos, discursos e tradições escolares.

\section{História PÚblica e tRajetóRIAS DOCENTES:}

\section{DO ACERVO À APRENDIZAGEM NARRATIVA}

O acervo digital Trajetórias Docentes reúne narrativas (auto)biográficas de professores de história em formação inicial e continuada (memoriais e entrevistas públicas), em um trabalho de memória que amplia e aprofunda as relações entre universidade e escola. O projeto para a construção do acervo leva em consideração este "fazer com" - o encontro entre os saberes escolares, acadêmicos e comunitários para a construção das memórias sobre a carreira e as inventividades docentes - por meio de narrativas (auto)biográficas. A explicitação narrativa de um saber profissional docente, construída pelos próprios sujeitos, ocorreu no âmbito de três processos institucionais de formação: inicial - licenciandos do Pibid, o Programa Institucional de Bolsas de Iniciação à Docência (15 memoriais) - e continuada - supervisores do PIRP, o Programa Institucional de Residência Pedagógica (4 entrevistas públicas) e docentes, mestrandos do ProfHistória, Mestrado Profissional em Ensino de História em Rede Nacional (18 memoriais).

A leitura das Trajetórias Docentes construídas por meio dessas narrativas (auto)biográficas possibilita algumas indagações, tais como: a que práticas inventivas remetem e/ou se destinam? Qual o lugar das inventividades no percurso da carreira e na construção narrativa do presente? Pressupondo que o tempo se torna tempo humano à medida que é narrado (Ricoeur, 1994), é possível observar os sentidos atribuídos pelos professores e licenciandos a suas histórias de vida, no processo de tornar-se professor, documentado nos materiais reunidos no acervo. Catalogadas e arquivadas digitalmente, as narrativas (auto)biográficas apontam para a necessidade de repensar o significado da formação (inicial, continuada) de professores em tempos sombrios, contexto em que o saber profissional encontra-se fortemente questionado e confrontado por perspectivas neoconservadoras e neoliberais, consubstanciadas naquilo que Apple (2011) denomina de restauração conservadora, contribuindo, desse modo, para a valorização profissional dos professores. 
Para a leitura das narrativas (auto)biográficas, interessa a interpretação de processos que levam alguém a se tornar professor. Afinal, como alguém se torna professor de história? Como se aprende a profissão e como se dá a inscrição dessa aprendizagem numa história de vida? É possível surpreender um saber da profissão nas narrativas de professores, sem contudo dissociá-lo da área disciplinar de sua formação?

$\mathrm{O}$ acervo nasceu de preocupações referentes à profissão docente, na interface entre História Pública e Educação, ${ }^{7}$ das quais emergiu uma série de produções dos organizadores e colaboradores: a disponibilização digital do acervo na página do LABHOI/UFF; um e-book, intitulado Trajetórias docentes: professores de História narram suas histórias na profissão (Andrade; Barreto, 2019), reunindo uma parte dos memoriais do acervo, incluindo as narrativas (auto)biográficas dos organizadores e apresentados por um breve estudo introdutório; dois projetos de Iniciação Científica vinculados ao manejo do acervo, incluindo gravações, transcrições e aportes digitais; eventos cotidianos nos ambientes acadêmico e escolar, inspirando até mesmo práticas no âmbito do Pibid e do PIRP etc. A partir desses esforços, o projeto Trajetórias Docentes buscou fortalecer os sentidos autobiográficos para construção de uma história pública das carreiras e inventividades docentes - operando com o conceito de aprendizado narrativo (Goodson, 2004), além de contribuir para o aprofundamento da relação entre a universidade e a escola, visando a composição do acervo.

Nas narrativas docentes, professores em formação (inicial e continuada), sujeitos de suas próprias práticas, reivindicam seu protagonismo nos discursos sobre a profissão e a educação, além de confrontar aquilo que muitas vezes se apresenta nos discursos oficiais como boas práticas, criando produções pedagógicas que nem sempre circulam nos meios públicos disponíveis - o que talvez justifique, pelo menos em parte, a afirmação de Shulman (1987), citada do início deste trabalho, segundo a qual "o ensino é desprovido de uma história das práticas”. Para além das entrevistas públicas, o projeto recebeu e disponibilizou os memoriais dos professores, criando formas de acesso às narrativas: digitalização, transferência e catalogação do material. ${ }^{8}$

Decorrem do acervo múltiplas possibilidades de análise sobre a produção de sentido e presença, por meio das histórias de vida dos professores, a partir do conceito de aprendizagem narrativa. Segundo Goodson, são sempre "vidas 
que aprendem", não cérebros. Nesse sentido, o autor ressalta a importância do emprego da narrativa nos estudos que visam compreender o currículo, a escola e a atuação profissional do docente (Goodson, 2008, p. 152). Entretanto, discutindo propostas de aprendizagem docente e desenvolvimento profissional, António Nóvoa sugere a necessidade de reforçar a "dimensão pessoal e a presença pública dos professores" rumo a uma teoria da pessoalidade, inscrita em uma teoria da profissionalidade, na qual se reconheça "o sentido de uma profissão que não cabe apenas numa matriz técnica ou científica” (Nóvoa, 2011, p. 536). Evidentemente, essa teoria da pessoalidade deverá incorporar não só interesses, propósitos e experiências, crenças e missões pessoais, paixões, sonhos, compromissos e propósitos dos professores, como também suas marcas de classe, gênero, raça e orientação sexual, as marcas das lutas sociais e políticas das quais participam, enfim, tudo aquilo que faz de cada um de nós uma "pessoa comum".

Pressupondo que "a história de uma vida pode explicar as reações de aprendizagem de uma pessoa", Goodson define que aprendizado narrativo é o "que ocorre durante a elaboração e a manutenção contínua de uma narrativa de vida ou identidade", isto é, de uma "missão de vida" ou de um enredamento com sentido para quem vive. Aprendizado narrativo é, pois, segundo Goodson (2008, p. 154), "uma das estratégias que as pessoas usam em reação a eventos em suas vidas" (p. 154). Nesse sentido, a abordagem do autor pressupõe a questão central do "envolvimento", significando que o aprendizado é contextualizado, circunscrito à história de vida de uma pessoa e tem, ele próprio, uma história: a história da vida do indivíduo, a história das instituições que oferecem oportunidades formais de aprendizagem e também a história das comunidades onde ocorre o aprendizado informal. O aprendizado narrativo é, por fim, uma reação a transições e experiências existenciais críticas, que podem ser incidentais (doenças, desemprego ou crise doméstica, por exemplo) ou estruturadas (credenciamento, aposentadoria etc.).

Nas trajetórias de professores, além da potencialidade para aprendizagem narrativa a partir da formação e do trabalho docente, existe a possibilidade de subsidiar (com base nos argumentos autobiográficos) propostas para políticas públicas, permitindo partilhar e compreender, por fim, o sentido da vida e da história nas práticas sociais (Bragança; Lima, 2016). A marca da heterogeneidade e do cruzamento de fronteiras, convidando ao intercâmbio entre 
professores e estudantes, pesquisadores e profissionais, confere ao acervo um caráter interinstitucional e transdisciplinar que fortalece a convergência entre História Pública e Educação.

\section{CONSIDERAÇÕES FINAIS}

No Brasil, as discussões sobre dimensões do público na história motivaram preocupações com as demandas sociais a partir dos trabalhos de memória. Dentre as várias possibilidades da História Pública, o presente texto assume o itinerário da história colaborativa: uma "história feita com o público" (Santhiago, 2016, p.28). As trajetórias docentes, enquanto comunidade de sentido, ${ }^{9}$ apontam narrativas políticas e apresentam experiências, reivindicações, estratégias e debates públicos. Uma História Pública com professores indica práticas de responsabilidade político-social com a memória coletiva (Ferreira, 2012; Almeida, 2016). Esse movimento, para a coprodução do saber problematizado sobre o tempo histórico, estimula o exercício colaborativo da autoridade compartilhada - encontro entre a escola (professores integrantes do projeto trajetória docentes) e a universidade (estudantes, professores e pesquisadores acadêmicos) com reivindicações particulares, que podem ser avaliadas e relacionadas "por meio daqueles encontros importantes que o cenário da história pública pode apoiar e estimular” (Frisch, 2016, p. 60).

A diversidade de leituras e procedimentos, nesse movimento da História Pública, expressa aprendizados e transformações por meio dos passados presentes - histórias de vidas (de professores) alimentadas por questões socialmente vivas, no tempo presente, com potência para ressignificar politicamente a memória social sobre a docência em história no Brasil. Ao envolver sujeitos, no trânsito entre a cultura acadêmica e a escolar, em colaboração, as demandas coletivas podem alicerçar projetos comunitários.

O distanciamento e os mútuos silenciamentos que por vezes aprofundam o abismo entre universidade e escola, particularmente no cenário educacional em que se desenham os "tempos sombrios" a que se referem Selles e Andrade (2016), recuperando Brecht e o poema “Aos que virão depois de nós”, além de nocivos em muitas instâncias, evidenciam a importância política da pesquisa construída na fronteira entre a Educação, a história e os campos disciplinares. Com o acirramento das disputas em torno do que se ensina, ou ainda, do que 
se pode ou não ensinar, somado à desvalorização social dos professores da Educação Básica, cria-se um cenário de insegurança sobre esse saber/fazer profissional, que tende de forma mais veemente para a regulação, limitando espaços de constituição da autonomia de professores.

Nesse sentido, o acervo Trajetórias Docentes está atento às necessidades, aos movimentos, aos interesses coletivos e aos imaginários dos sujeitos históricos envolvidos. As formas como esses sujeitos realizam trabalhos de memória, por meio de experiências narrativas, apontam vivências compartilhadas para reconstrução do passado, do presente e das expectativas futuras. Diante disso, a construção de modos de entendimento das Artes de Ensinar se coloca mais intensamente como necessidade na medida em que "aprender com" e "dialogar com" as inventividades docentes torna-se uma forma de resistência solidária aos ataques feitos à profissão, com vias de potencializar a escola como aliada na construção de saberes legítimos para promoção de uma educação mais igualitária em termos étnicos e raciais, assim como religiosos, sexuais e de gênero.

A esse respeito, porém, em que pese a euforia dos vitoriosos do momento, resta dizer que, na história, sempre estarão rolando os dados...

\section{REFERÊNCIAS}

ALMEIDA. Juniele R. História oral e movimento social: narrativas públicas. São Paulo: Letra e Voz, 2016. (Coleção História Oral e Dimensões do Público).

ALMEIDA, Juniele R.; MENESES, Sônia (org.). História pública em debate: patrimônio, educação e mediações do passado. São Paulo: Letra e Voz, 2018.

ALMEIDA. Juniele R.; ROVAI, Marta G. de O. (Org.). Introdução à História Pública. São Paulo: Letra e Voz, 2012.

ANDRADE, Everardo P. de; ALMEIDA, Juniele R. Trajetórias docentes e história pública: a construção de um acervo com narrativas de professores. In: ALMEIDA, Juniele R.; MENESES, Sônia (org.). História pública em debate: patrimônio, educação e mediações do passado. São Paulo: Letra e Voz, 2018.

ANDRADE, Everardo P. de; BARRETO, Marcos P. (org.). Trajetórias docentes: professores de História narram suas histórias na profissão. Rio de Janeiro: E-papers, 2019. 
APPLE, Michael W. A política do conhecimento oficial: faz sentido a ideia de um currículo nacional? In: MOREIRA, Antonio Flavio; TADEU, Tomaz (org.). Currículo, cultura e sociedade. 12. ed. São Paulo: Cortez, 2011. p. 71-106.

BACZKO, Bronislaw. Imaginação social. In: ENCICLOPÉDIA Einaudi. Lisboa: Imprensa Nacional/Casa da Moeda: Ed. Portuguesa, 1985.

BRAGANÇA, Inês F. de S.; LIMA, Rita P. Narrativas de vida de instrutores da educação profissional como possibilidade de estudos no campo das representações sociais. Revista Brasileira de Estudos Pedagógicos (online). Brasília, DF, v. 97, n. 246, maio/ago. 2016.

CERTEAU, Michel de. A invenção do cotidiano: 1. Artes do fazer. 3. ed. Petrópolis: Vozes, 1998.

CERTEAU, Michel de; GIARD, Luce; MAYOL, Pierre. A invenção do cotidiano - 2. Morar, cozinhar. 12. ed. Petrópolis: Vozes, 2013.

FERRAROTTI, Franco. Sobre a autonomia do método biográfico. In: NÓVOA, António; FINGER, Matthias (org.) O método (auto)biográfico e a formação. 2. ed. Natal: Ed. UFRN, 2014.

FERREIRA, Marieta de M. Demandas sociais e História do Tempo Presente. In: VARELLA, Flávia F. et al. (org.). Tempo presente \& usos do passado. Rio de Janeiro: Ed. FGV, 2012.

FONSECA, Selva G. Ser professor no Brasil: história oral de vida. Campinas: Papirus, 1997.

FRISCH, Michael. A história pública não é uma via de mão única, ou, De A Shared Authority à cozinha digital, e vice冈versa. In: MAUAD, Ana Maria; ALMEIDA, Juniele R.; SANTHIAGO, Ricardo (org.). História pública no Brasil: sentidos e itinerários. São Paulo: Letra e Voz, 2016. p. 57囚71.

GAUTHIER, Clermont; MARTINEAU, Stéphane; DESBIENS, Jean-François; MALO, Annie; SIMARD, Denis. Por uma teoria da pedagogia: pesquisas contemporâneas sobre o saber docente. 2. ed. Ijuí: Ed. Unijuí, 2006.

GOODSON, Ivor F. Dar voz ao professor: as histórias de vida dos professores e o seu desenvolvimento profissional. In: NÓVOA, António (org.). Vidas de professores. Porto: Porto Ed., 1992.

GOODSON, Ivor F. Developing Life and Works Histories of Teachers (Desenvolvendo histórias de vida e de trabalho de professores). In: ABRAHÃO, Maria Helena M. B. (org.). A aventura (auto)biográfica: teoria e empiria, CIPA 1 (The Autobiographic Adventure: Theory and Practice). Porto Alegre: Ed. PUCRS, 2004.

GOODSON, Ivor F. As políticas de currículo e de escolarização: abordagens históricas. Petrópolis: Vozes, 2008. 
GUMBRECHT, Hans Ulrich. Produção de presença: o que o sentido não consegue transmitir. Rio de Janeiro: Contraponto: Ed. PUC-Rio, 2010.

HUBERMAN, Michael. O ciclo de vida profissional dos professores. In: NÓVOA, António (org.). Vidas de professores. Porto: Porto Ed., 1992.

MAUAD, Ana Maria; ALMEIDA, Juniele R.; SANTHIAGO, Ricardo (org.). História Pública no Brasil: sentidos e itinerários. São Paulo: Letra e Voz, 2016.

MAUAD, Ana Maria; SANTHIAGO, Ricardo; BORGES, Viviane (org.). Que História Pública queremos? What Public History do We Want? São Paulo: Letra e Voz, 2018.

MONTEIRO, Ana Maria. Professores de História: entre saberes e práticas. Rio de Janeiro: Mauad, 2007.

NÓVOA, António. Firmar a posição como professor, afirmar a profissão docente. Caderno de Pesquisa [online], v. 47, n. 166, 2017.

NÓVOA, António. Pesquisa em educação como processo dinâmico, aberto e imaginativo: uma entrevista com António Nóvoa. Educação \& Realidade, Porto Alegre, v. 36, n. 2, maio/ago. 2011.

NÓVOA, António (org.). Vidas de professores. Porto: Porto Ed., 1992.

NÓVOA, António; FINGER, Matthias. Introdução. In: NÓVOA, António; FINGER, Matthias (org.). O método (auto)biográfico e a formação. 2. ed. Natal: Ed. UFRN, 2014.

PASSEGGI, Maria da Conceição. Memoriais auto-bio-gráficos: a arte profissional de tecer uma figura pública de si. In: PASSEGGI, Maria da Conceição; BARBOSA, Tatyana M. N. (org.). Memórias, memoriais: pesquisa e formação docente [CIPA 5]. Natal: Ed. UFRN; São Paulo: Paulus, 2008. p. 27-42.

PASSEGGI, Maria da Conceição. A pesquisa (auto)biográfica: por uma hermenêutica descolonizadora. Coisas do Gênero, São Leopoldo (RS), v. 2, n. 2, ago./dez. 2016.

PASSEGGI, Maria da Conceição; SOUZA, Elizeu C. O movimento (auto)biográfico no Brasil: esboço de suas configurações no campo educacional. Revista Investigación Cualitativa, v. 2, n. 1, p. 6-26, 2017.

POLLAK, Michael. Memória, esquecimento, silêncio. Estudos Históricos, Rio de Janeiro, v. 2, n. 3, p. 3-15, 1989.

RICOEUR, Paul. Tempo e narrativa. Campinas: Papirus, 1994.

SELLES, Sandra E.; ANDRADE, Everardo P. de. Políticas curriculares e subalternização do trabalho docente. Educação em Foco, Juiz de Fora: Faculdade de Educação, UFJF, v. 21, n. 1, mar./jun. 2016.

SHULMAN, Lee S. Knowledge and Teaching: Fundations of the New Reform. Harvard Educational Review, v. 57, n. 1, 1987. 
TARDIF, Maurice. As concepções do saber dos professores de acordo com diferentes tradições teóricas e intelectuais. Rio de Janeiro: Ed. PUC-Rio, 2000.

TARDIF, Maurice. Os professores diante do saber: esboço de uma problemática do saber docente. In: TARDIF, Maurice. Saberes docentes e formação profissional. Petrópolis: Vozes, 2002.

ZUMTHOR, Paul. Performance, recepção, leitura. São Paulo: Cosac Naify, 2014.

\section{NOTAS}

${ }^{1}$ Doutor em Educação (UFF), vice-coordenador do Grupo de Pesquisa Currículo, Docência \& Cultura (CDC) da Faculdade de Educação da UFF e Coordenação do Programa Residência Pedagógica em História (PIRP História UFF-Capes).

${ }^{2}$ Doutora em História Social (USP), pesquisadora da equipe de coordenação do Laboratório de História Oral e Imagem (LABHOI/UFF) e Coordenação do Programa Residência Pedagógica em História (PIRP História UFF-Capes).

${ }^{3}$ Mestre em Educação pelo Programa de Pós-graduação em Educação da Universidade Federal Fluminense (UFF), onde integra o Grupo de Pesquisa Currículo, Docência \& Cultura (CDC).

${ }^{4}$ Projeto que envolve a parceria do Laboratório de História Oral e Imagem (LABHOI) e do Laboratório de Ensino de História (LEH), sob a responsabilidade compartilhada, respectivamente, por professores do Instituto de História e da Faculdade de Educação, na Universidade Federal Fluminense (UFF). O projeto, além de buscar o diálogo entre unidades universitárias distintas tendo em vista a ultrapassagem de dicotomias que separam a área de conhecimento e a formação pedagógica, reunidas em torno de um projeto de formação docente, articula políticas públicas da Capes, de formação inicial e continuada de professores - o Programa Institucional de Bolsas de Iniciação à Docência (Pibid), o Programa Institucional de Residência Pedagógica (PIRP) e o Mestrado Profissional em Ensino de História em Rede Nacional (ProfHistória). Alguns dados técnicos do Acervo Trajetórias Docentes (Storage LABHOI/UFF - www.labhoi.uff.b): Material: 18 narrativas autobiográficas dos professores em formação continuada; 15 narrativas autobiográficas dos professores em formação inicial; 4 entrevistas públicas (material audiovisual - canal Trajetórias Docentes no YouTube). Professores responsáveis: Everardo Paiva Andrade, Juniele Rabêlo de Almeida. Bolsistas de Iniciação Científica: Daniela Rocha e Juliana Reis. Organização do site: Ana Paula Serrano. Professores Colaboradores: Marcos Barreto, Larissa Viana, Rodrigo de Almeida Ferreira e Patrícia Teixeira de Sá.

${ }^{5} \mathrm{O}$ conceito de aprendizagem narrativa (GOODSON, 2008, p. 154) articula o "envolvimento" e a contextualização circunscrita à história de vida narrada, que oferece oportunidades de aprendizagem. 
${ }^{6}$ Ao construir pontes entre os diferentes saberes, a história pública ultrapassa a ideia de acesso e publicização de projetos acadêmicos e busca a produção e a difusão compartilhada do conhecimento. No Brasil, os debates sobre história pública se relacionam com discussões sobre os públicos da história, formas narrativas e processos de construção/difusão compartilhada do conhecimento produzido entre a universidade, a academia e as comunidades de sentido - em projetos que envolvem, necessariamente, os públicos aos quais se destinam. Cabe indicar a importância dos diversos dossiês, em revistas acadêmicas brasileiras, sobre o tema a partir do ano de 2012, bem como obras organizadas a partir dos encontros internacionais da Rede Brasileira de História Pública (ALMEIDA; ROVAI, 2012; MAUAD; ALMEIDA; SANTHIAGO, 2016; ALMEIDA; MENESES, 2018; MAUAD; SANTHIAGO; BORGES, 2018).

${ }^{7}$ Sobre o projeto "Trajetórias docentes e história pública" e o processo de construção de um acervo com narrativas de professores, ver Andrade; Almeida (2018).

${ }^{8}$ Material digitalizado no âmbito do projeto Trajetórias Docentes para o storage do LABHOI, facilitando o acesso público - com a criação de perfis específicos - ao material pesquisado, e finalmente atualização, com a transferência dos materiais do site (www.labhoi.uff.br).

${ }^{9}$ Uma comunidade de sentido se expressa por memórias plurais, produzidas historicamente, a partir da experiência social de uma coletividade. O trabalho de memória do grupo, enquanto comunidade de sentido, ressignifica o tempo por meio da construção de representações do passado (BACZKO, 1985; POLLAK, 1989).

Artigo recebido em 14 de abril de 2019. Aprovado em 3 de julho de 2019. 